DOI: https://doi.org/10.46296/yc.v4i7edespdic.0079

\title{
TRANSPORTE TERRESTRE PÚBLICO Y SU INCIDENCIA EN LA DEMANDA TURÍSTICA DEL CANTÓN SUCRE - MANABÍ
}

\section{PUBLIC LAND TRANSPORT AND ITS IMPACT ON THE CANTON SUCRE - MANABÍ TOURIST MARKET}

\author{
Zambrano-Cedeño Jessica Mariela1*; Nevárez-Barbarán José Víctor², Caicedo-Coello \\ Jimmy Alberto ${ }^{3}$
}

\author{
${ }^{1}$ Profesora de la Universidad Laica Eloy Alfaro de Manabí. Bahía de Caráquez, \\ Ecuador. Universidad de Camagüey Ignacio Agromonte Loynaz. Camagüey, Cuba. \\ Orcid: https://orcid.org/0000-0003-1370-5934 \\ 2 Profesor de la Universidad Laica Eloy Alfaro de Manabí. Bahía de Caráquez, \\ Ecuador. Universidad Metropolitana del Ecuador. Guayaquil, Ecuador. Orcid: \\ https://orcid.org/0000-0002-4377-6867 \\ ${ }^{3}$ Profesor de la Universidad Laica Eloy Alfaro de Manabí. Bahía de Caráquez, \\ Ecuador. Orcid: https://orcid.org/0000-0003-3869-9905
}

*Correo: jessica.zambrano@uleam.edu.ec

\begin{abstract}
Resumen
Los medios de transporte juegan un papel preponderante en el mercado turístico para tal efecto se realizó una investigación usando el método analítico descriptivo donde se abordó las definiciones del transporte terrestre y mercado turístico en general y específicamente del cantón Sucre, lo que permitió conocer el objeto de estudio y su movilidad en el espacio. Se desarrolló un diagnóstico de la oferta y demanda del transporte terrestre en la oferta se tomó como muestra los transportes: Moto taxis, cooperativas de taxi y cooperativa de transporte Tosagua; las dos primeras del servicio interno y la tercera de trasporte inter cantonal; el $40 \%$ viaja por trabajo y no son del cantón Sucre y les gustaría recibir información en las unidades de transporte, un $20 \%$ se dirige a las playas son extranjeros, $40 \%$ son habitantes del lugar. En la encuesta a los prestadores de servicio de transporte resultó que desconocen los recursos y atractivos turísticos del cantón Sucre un $25 \%$, promocionan como ciudad de descanso $25 \%$ y promocionan solo las playas el $50 \%$. Se direccionó una entrevista dirigida a los representantes de las cooperativas de transporte en cuestión un $86 \%$ están dispuestos a recibir orientaciones turísticas por parte de los organismos competentes y un $14 \%$ solo que sea una exigencia para laborar. Por medio de la observación se ratifica que no hay material publicitario de Turismo en las unidades de transporte. Se concluye que los actores del transporte terrestre deben aportar orientaciones claras y precisas al viajero, pues la calidad de información recibida por estos medios influye significativamente en la receptividad del turismo para el cantón Sucre.
\end{abstract}

Palabras claves: Transporte público, Turismo, Demanda turística, Turista, Excursionista.

\begin{abstract}
The means of transport play a preponderant role in the tourism market for this purpose, an investigation was carried out using the descriptive analytical method where the definitions of land transport and the tourist market in general and specifically of the Sucre canton were addressed, which allowed to know the object of study and its mobility in space. A diagnosis of the supply and demand of land transport was developed. The supply was taken as a sample of transports: Moto taxis, taxi cooperatives and Tosagua transport cooperative; the first two for internal service and the third for inter cantonal transportation; $40 \%$ travel for work and are not from the Sucre canton and would like to receive information in the transport units, $20 \%$ go to the beaches are foreigners, $40 \%$ are local inhabitants. In the survey of transport service providers, it was found that $25 \%$ are Información del manuscrito:
\end{abstract}

Fecha de recepción: 05 de noviembre de 2020.

Fecha de aceptación: 14 de diciembre de 2020.

Fecha de publicación: 21 de diciembre de 2020. 
unaware of the resources and tourist attractions of the Sucre canton, $25 \%$ promote as a city of rest and $50 \%$ promote only the beaches. An interview was directed to the representatives of the transport cooperatives in question, $86 \%$ are willing to receive tourist guidance from the competent bodies and $14 \%$ only that it is a requirement to work. Through observation it is confirmed that there is no tourism advertising material in the transport units. It is concluded that land transport actors must provide clear and precise guidelines to the traveler, since the quality of information received by these means significantly influences the receptivity of tourism to the Sucre municipality.

Keywords: Public transport, tourism, Tourist demand, Tourist, Hiker.

\section{Introducción}

El cantón Sucre perteneciente a la provincia de Manabí del Ecuador, tiene una población de 57.159 habitantes, su cabecera cantonal es la ciudad de Bahía de Caráquez. Sus límites son al norte con el Cantón San Vicente, al sur con los cantones Portoviejo y Rocafuerte, al este con los cantones Tosagua y Rocafuerte; tiene una extensión de 764 km².

Entre las principales actividades productivas de esta región, está la producción camaronera que genera divisas para el país, así como también la agricultura, ganadería, avicultura, comercio, pesca y turismo.

Las actividades económicas sin lugar a duda hacen uso de la transportación para comercializar sus productos, definiéndolo como un componente importante para el traslado; para sus efectos las de servicio requieren desplazamiento de los demandantes, turistas 0 visitantes para llevarlos al destino y poder crear la experiencia según cada necesidad siendo la comunicación en los medios de transporte lo que puede genera expectativas positivas o negativas en los usuarios según la cognición proporcionada. (Castaño y valencia, 2016)

Existe la necesidad de que se informe a la demanda turística actual sobre la diversidad de destinos turísticos locales y actividades que en ellos se puede desarrollar, además se motive el interés por las actividades turísticas del cantón Sucre y como efecto surjan clientes potenciales. Se avizora al transporte público como uno de los medios fundamentales para fomentar la promoción turística del cantón Sucre y que actúe como un mecanismo alternativo para captar clientes. Se considera 'esencial' que las industrias de transporte y el turismo 
trabajen 'mano a mano' (Currie y

Falconer, 2013).

El propósito de la investigación fue indagar en la oferta y demanda existente de los medios de transporte, los motivos de viaje del cliente, la información turística que se proporciona en los medios de transporte sobre el cantón Sucre y la predisposición de los directivos gremiales de los transportes públicos a trabajar como mecanismo utilitario para el desarrollo del turismo del cantón Sucre.

\subsection{Antecedentes}

Para la población manabita el transporte público es de vital importancia para cargas de producto y transporte de personas; sin embargo, no deja de ser visto como un servicio peyorativo, sin indagar en una investigación que permita tener acercamiento real a la valoración de la oferta.

La calidad del servicio ofrecido por un operador de transporte es función de la propia capacidad operativa, organizativa y de gestión, tal y como sucede en cualquier empresa; además existen otros factores externos que determinan la forma de percepción de las personas usuarias del servicio. (Prieto,2019)

Las cooperativas de transporte público terrestre correspondientes a la muestra de estudio, en algún momento promocionaron destinos turísticos del cantón Sucre impulsados por el gobierno local por medio de afiches, pero se ausentó la capacitación, lo que limitó a los transportistas a dar información de otros destinos a más de las playas.

Cabe señalar que el turismo está intrínsecamente ligado a un desplazamiento, dentro del cual se encuentra contemplado algún medio de transporte, porque de nada sirve contar con un atractivo turístico si no hay acceso a él (Viloria, 2012)

Los excursionistas y turistas se movilizan dentro de la cabecera cantonal hasta sus playas más cercanas en diferentes medios de trasporte (moto taxis, cooperativa de transporte Tosagua, cooperativas de taxis y vehículos particulares) con escaza afluencia hacia otros destinos debido a que hay desconocimiento por propios $y$ extraños.

Hay ausencia de investigaciones sobre la oferta del servicio de 
transportación pública terrestre y la incidencia de la demanda turística de destinos del cantón Sucre; por ello se incurre en la presente investigación para avizorar elementos que permitan dinamizar el mercado turístico por medio del transporte público.

\subsection{Transporte terrestre}

Según Pérez \& Gardey (2012). El concepto y definición de transporte se utiliza para describir al acto y consecuencia de trasladar algo de un lugar a otro. También permite nombrar a aquellos artilugios o vehículos que sirven para tal efecto, llevando individuos o mercaderías desde un determinado sitio hasta otro. Se habla de transporte público, para hacer referencia a los autobuses, trenes y otras unidades móviles que sirven para la movilización de los ciudadanos de una comunidad y que está solventado y manejado por el Estado vigente. Cabe señalar en algunos casos, dichos coches pertenecen a empresas privadas que tienen algún tipo de acuerdo con el gobierno y han asumido la responsabilidad de brindar un servicio determinado a la comunidad. El transporte privado, en cambio, es el que pertenece a individuos o empresas particulares. En este caso los responsables de la manutención de dichos vehículos son sus dueños, al igual que serán quienes respondan por ellos en caso de accidente.

El transporte se refiere al movimiento de un producto de un lugar a otro en su recorrido desde el principio de la cadena de suministro hasta el cliente. (CHOPRA, Administración de la cadena de suministro).

Se denomina transporte a un sistema formado por múltiples elementos, siendo tres los fundamentales, la infraestructura, el vehículo y la empresa de servicio que viene a constituir la actividad previamente dicha. Estos elementos están interrelacionados entre sí, pues ninguno es útil sin que los otros existiesen. (CENDRERO, el transporte: aspectos y su tipología).

1. Turismo: El turismo es un fenómeno social, cultural y económico que supone el desplazamiento de personas a países o lugares fuera de su entorno habitual por motivos personales, profesionales o de negocios.

2. Turista: Es la persona que viaja con fines recreativos, laborales y 
de salud fuera del lugar de su residencia.

3. Excursionista: Es quien viaja a un lugar determinado fuera de su entorno habitual por menos de 24 horas

4. Demanda turística: Se define como demanda al conjunto de consumidores 0 posibles consumidores de bienes y servicios turísticos que buscan satisfacer sus necesidades de viaje. Sean éstos los turistas, viajeros y visitantes, independientemente de las motivaciones que les animan a viajar y del lugar que visitan o planean visitar. La demanda turística comprende un grupo heterogéneo de personas con diferentes características sociodemográficas, motivaciones y experiencias, que, influenciadas por sus intereses y necesidades particulares, desean, pueden y están dispuestos a disfrutar de las facilidades, atractivos, actividades, bienes o servicios turísticos. La demanda está directamente relacionada con la toma de decisiones que los individuos realizan en la planificación de sus actividades de ocio, cuando se trata de viajes de recreación y familiares o bien de sus ocupaciones profesionales, cuando se trata de viajes de negocios.

\section{Metodología}

Se abordó el análisis bibliográfico para definir al transporte terrestre público y la demanda turística. La utilización del método descriptivo fue para especificar las acciones de los transportistas y usuarios hacia el turismo del cantón Sucre; la instrumentación se desarrolló a través de encuestas, dirigida a los choferes de los distintos medios de transportes y los usuarios que utilizan este servicio; las entrevistas fueron direccionadas a los 4 gerentes gremiales. La muestra fue aleatoria representativa; la aplicación de encuesta estuvo contemplada en 150 usuarios del servicio (pasajeros),30 choferes oficiales y la observación a 30 unidades de transporte para confirmar q no existe material de difusión turística. 


\section{Resultados y discusión}

En la aplicación de instrumentos como la encuesta y la entrevista se constató que la mayoría de los choferes y oficiales carecen de información sobre los destinos turísticos del cantón Sucre evidenciándolo cuando la mitad de la muestra solo oferta playas y una cuarta parte explican que es una ciudad para descansar, y los restantes reconocen su desconocimiento, además se observó que en las unidades de transporte hay ausencia de material publicitario con este propósito. Los gerentes de las cooperativas atendidas en la investigación consideran importante la capacitación en el área que proceda de las autoridades cantonales y universidades de la localidad.

Gráfico 1. Frecuencia de pasajeros por actividad

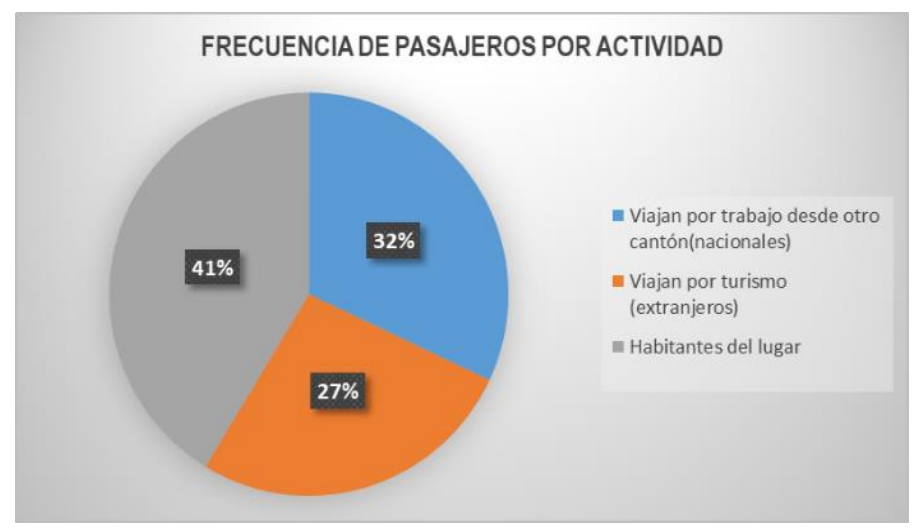

Fuente: Autores, (2020)
Se tomó una muestra de 150 pasajeros, de los cuales 62 son habitantes del lugar, 40 viajan por turismo,48 viajan por trabajo y son de otro cantón.

Gráfico 2. Conocimientos de destinos turísticos del cantón (choferes y oficiales)

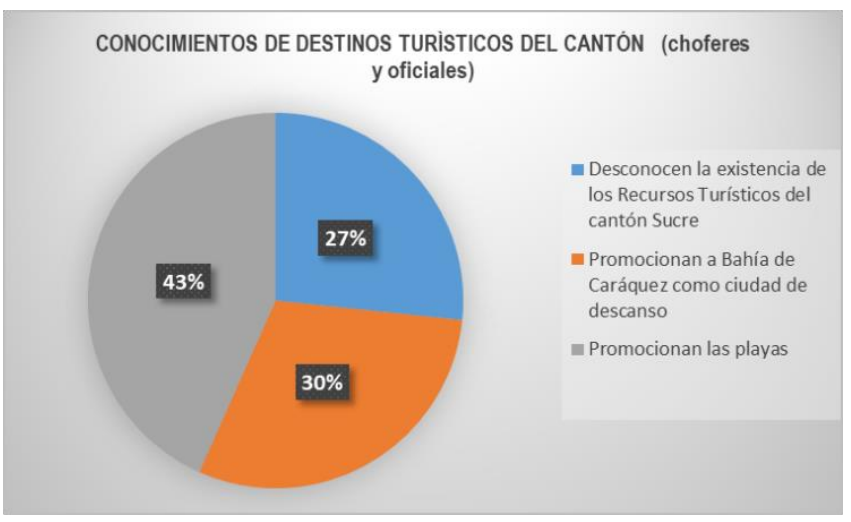

Fuente: Autores, (2020)

La muestra es de 30 personas encargadas del transporte .13 proporcionan información de las playas, 9 promocionan a Bahía de Caráquez como ciudad de descanso,8 desconocen de la existencia de recursos turísticos.

\section{Conclusiones}

Hay una fuerte movilidad humana local, nacional y extranjera que se sirve del transporte público ,razón para usar estos medios como complemento difusor de destinos turísticos , para su efecto, se ultima por medio del análisis de datos la necesidad de capacitar a los 
prestadores de servicio de transporte público en temáticas de atención al cliente y destinos turísticos del cantón Sucre convirtiéndolos en promotores de las bondades turísticas, ayudando a fortalecer esta demanda desde su espacio laboral; para ello se requiere de alianzas estratégicas del sector educativo superior y el gobierno autónomo descentralizado local que garanticen el desarrollo eficiente de la formación y acción.

\section{Bibliografía}

Castaño M; Valencia, A. (2016). El papel del transporte en el desarrollo de la actividad turística:un análisis biométrico. Revista Geográfica Venezolana, vol. 57, núm. 2, 2016, pag: 55-64 disponible:

https://www.redalyc.org/articu lo.oa?id=347750606007.

Currie, C. \& Falconer, P. (2013). "Maintaining sustainable island destinations in Scotland: The role of the transport-tourism

relationship". Journal of

Destination Marketing \& Management, 3(3), 162-172.

Pérez, J; Gardey, A. (2012). Definiciones de Transporte. Publicacion mensual Adventure Works, disponible: https://definicion.de/transport e/.

Prieto, J. (2019). Investigación de Mercados; segunda edición . Suiza: ECOE Ediciones.

Viloria, N. (2012). Desarrollo Turístico y su relación con el transporte. Gestión Turistica № 17, 23-36: Disponible: http://www.unwto.org/facts/en $\mathrm{g} /$ barometer. 